\title{
The appropriate management of persisting pain after spine surgery: a European panel study with recommendations based on the RAND/ UCLA method
}

\author{
Volker M. Tronnier ${ }^{1}$. Sam Eldabe ${ }^{2}$. Jörg Franke ${ }^{3}$. Frank Huygen ${ }^{4} \cdot$ Philippe Rigoard $^{5,6}$. Javier de Andres Ares ${ }^{7}$. \\ Richard Assaker $^{8} \cdot$ Alejandro Gomez-Rice $^{9} \cdot$ Marco La Grua $^{10}$. Maarten Moens ${ }^{11} \cdot$ Lieven Moke $^{12,13}$. \\ Christophe Perruchoud ${ }^{14}$. Nasir A. Quraishi ${ }^{15}$. Dominique A. Rothenfluh ${ }^{16}$. Pedram Tabatabaei ${ }^{17}$. \\ Koen Van Boxem ${ }^{18}$. Carmen Vleggeert-Lankamp ${ }^{19} \cdot$ Björn Zoëga $^{20} \cdot$ Herman J. Stoevelaar $^{21}$
}

Received: 29 May 2018 / Revised: 29 June 2018 / Accepted: 25 July 2018 / Published online: 4 August 2018

(c) The Author(s) 2018

\begin{abstract}
Purpose Management of patients with persisting pain after spine surgery (PPSS) shows significant variability, and there is limited evidence from clinical studies to support treatment choice in daily practice. This study aimed to develop patientspecific recommendations on the management of PPSS.

Methods Using the RAND/UCLA appropriateness method (RUAM), an international panel of 6 neurosurgeons, 6 pain specialists, and 6 orthopaedic surgeons assessed the appropriateness of 4 treatment options (conservative, minimally invasive, neurostimulation, and re-operation) for 210 clinical scenarios. These scenarios were unique combinations of patient characteristics considered relevant to treatment choice. Appropriateness had to be expressed on a 9-point scale $(1=$ extremely inappropriate, $9=$ extremely appropriate). A treatment was considered appropriate if the median score was $\geq 7$ in the absence of disagreement ( $\geq 1 / 3$ of ratings in each of the opposite sections 1-3 and 7-9).

Results Appropriateness outcomes showed clear and specific patterns. In $48 \%$ of the scenarios, exclusively one of the 4 treatments was appropriate. Conservative treatment was usually considered appropriate for patients without clear anatomic abnormalities and for those with new pain differing from the original symptoms. Neurostimulation was considered appropriate in the case of (predominant) neuropathic leg pain in the absence of conditions that may require surgical intervention. Re-operation could be considered for patients with recurrent disc, spinal/foraminal stenosis, or spinal instability.

Conclusions Using the RUAM, an international multidisciplinary panel established criteria for appropriate treatment choice in patients with PPSS. These may be helpful to educate physicians and to improve consistency and quality of care.
\end{abstract}

Electronic supplementary material The online version of this article (https://doi.org/10.1007/s00586-018-5711-0) contains supplementary material, which is available to authorized users.

Extended author information available on the last page of the article 
Graphical abstract These slides can be retrieved under Electronic Supplementary Material.
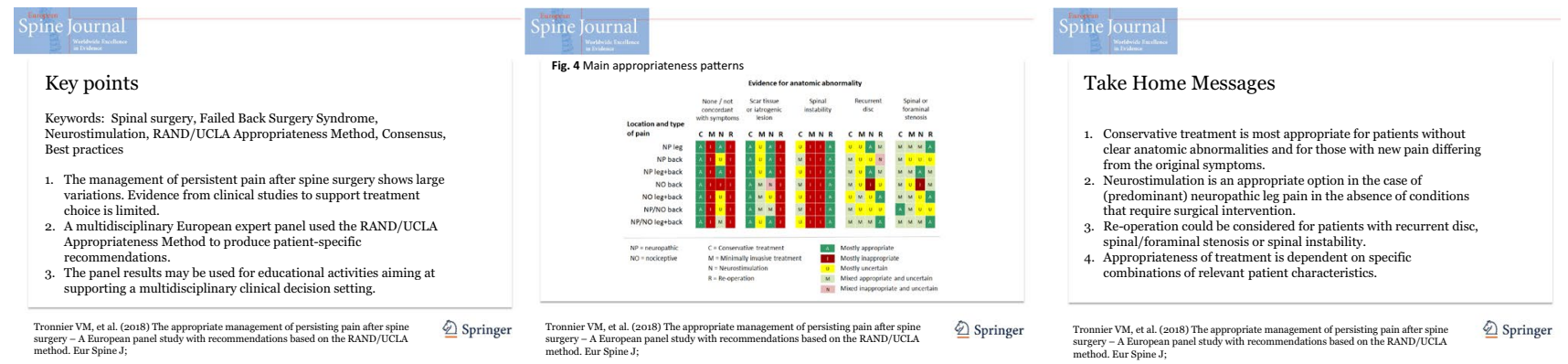

Keywords Spinal surgery · Failed back surgery syndrome · Neurostimulation · RAND/UCLA Appropriateness Method · Consensus

\section{Introduction}

Spinal decompression (including removal of herniated discs) and spinal fusion are frequently performed surgical procedures in patients with back and/or leg pain due to degenerative lumbar spine disease. In the UK, the frequency of this type of surgery increased from 25 to 49 per 100,000 in the population over the period 1999-2013 [1]. In the USA, the surgery rate is considerably higher (135 per 100,000 in 2013), but does not show a further increase [2].

Unfortunately, there is a considerable proportion of patients who experience recurrent or remaining pain following initial spine surgery, ranging from 3 to $34 \%$ at follow-up between 6 and 24 months after surgery, and 5 to $36 \%$ upon long-term evaluation ( $>2$ years) $[3,4]$. A recent populationbased cohort study in England reported that over the period 2007-2012 on average $20.8 \%$ of lumbar surgery patients experienced persistent post-operative pain [5]. Unsatisfactory results after spinal surgery are often referred to as "failed back surgery syndrome" (FBSS), but this term has been criticised because it unilaterally puts the blame on the operation as the cause of the problem, while the aetiology is much more complex and often multifactorial [6-9].

In a systematic review of 40 studies on lumbar discectomy, the predictive value of 95 preoperative factors for post-operative clinical outcomes was explored [10]. The study revealed 17 factors associated with a positive surgical outcome including more severe leg pain and better mental health status. A negative association with surgical outcome was seen for some anatomic characteristics, but also for patient-related social factors such as worker's compensation. For $61 \%$ of the factors, including age and sex, the results were not significant or conflicting [10]. A secondary analysis of the data from a randomised controlled trial (RCT) and subsequent cohort study on lumbar discectomy showed that the 1- and 3-year risk of recurrent pain was substantially lower in patients with complete initial resolution of leg pain [11]. Other predictive factors that are currently studied include the origin and nature of the pain (nociceptive versus neuropathic pain) [12-14], sagittal balance [15, 16], and anatomic characteristics such as the presence of root compression [17] and the type of stenosis [18].

For patients with persisting or recurrent pain after spinal surgery (PPSS), a variety of treatments is used, including conservative treatments (pain medication, physical therapy, psychological rehabilitation, and graded activity), neurostimulation, minimally invasive treatments (a.o selective nerve root blocks, facet and sacroiliac joint infiltration/denervation, epidural injections, often primarily used as a diagnostic procedure), and re-operation. Clinical studies on most of these treatment modalities are scarce and often of limited quality. Most (randomised controlled) clinical studies have been performed for spinal cord stimulation (SCS) [19] and some minimally invasive treatments [20]. A recent systematic review suggested epidural adhesiolysis to be effective in the short term [21]. SCS was shown to be efficacious in studies with a follow-up of 2-3 years, and proved to be more efficacious than conventional medical management and reoperation in distinct patient groups [19, 21]. For other treatments, including re-operation, the authors considered the evidence from available studies to be poor or inconclusive [21]. Similar outcomes were found in a recent comprehensive review in this journal, though the researchers suggested that there is also sufficient evidence to recommend active exercise as a treatment option [22].

The availability of many treatment modalities and limited evidence from clinical studies has induced large practice variations. This variability is further enlarged by the heterogeneity of the patient population and the (potential) involvement of different specialties in the management of 
PPSS (general practitioners, pain specialists, neurosurgeons, orthopaedic surgeons, neurologists, and rehabilitation physicians). A number of guidelines and algorithms focusing on, or including recommendations on the management of PPSS have been published [6, 23-27]. However, these are often either not very specific, or too much focused on single treatments or specialties. This study sought to establish patientspecific recommendations for the management of PPSS from a multidisciplinary perspective, combining evidence from clinical studies and practice experience of an international expert panel.

\section{Materials and methods}

The appropriateness of treatments for persisting pain after spine surgery (PPSS) was assessed using the RAND/UCLA Appropriateness Method (RUAM) [28]. This modified Delphi method has been used to establish appropriateness criteria for surgical, medical, and diagnostic procedures in various fields of medicine [29]. It aims at integrating scientific knowledge and clinical insights of experts to produce detailed statements "regarding the appropriateness of performing a procedure at the level of patient-specific symptoms, medical history, and test results" [29]. The method is particularly helpful when evidence from clinical studies is insufficient to cover the heterogeneity of patients seen in daily clinical practice [29]. The RUAM consists of a structured and iterative process of individual (independent and anonymous) rating rounds and plenary discussion meetings. Results of various methodological and outcome studies support the reliability, internal consistency, and clinical validity of the RUAM [30-35].

\section{Panel composition}

Panel composition was based on an equal representation of the 3 specialties that are most involved in the treatment of patients with PPSS: neurosurgery, pain medicine, and orthopaedic surgery. Individual panellists were selected on the basis of their scientific and clinical expertise, as well as their involvement in guideline development in the field of PPSS. Furthermore, a reasonable geographic spread over Europe was pursued. The panel included 6 neurosurgeons, 6 anaesthetists/pain specialists, and 6 orthopaedic surgeons from 9 European countries (Belgium, France, Germany, Italy, Spain, The Netherlands, Sweden, Switzerland, and the UK).

\section{Literature overview}

A literature study was conducted to support shaping the starting points of the study, and to ensure that participants had access to the same body of evidence during the panel process. To avoid interpretation bias, materials were provided as an overview, rather than as a review.

\section{Panel process}

The flow of the panel study is depicted in Fig. 1. During the first panel meeting (Amsterdam, October 2016), the panel discussed the patient population to be considered, treatments to be included, and factors that may be relevant to treatment choice.

The panel agreed to restrict the study to patients with:

(a) Persisting, recurrent, or new pain after previous spinal surgery for degenerative disease

(b) Symptom duration of $\geq 6$ months after disc or decompression surgery, and $\geq 12$ months after spinal fusion

(c) At least moderate symptoms (cf. VAS $\geq 4$ ) with at least moderate impact on daily functioning (based on, e.g. the Oswestry Disability Index or Roland Morris Disability Questionnaire) and quality of life (based on, e.g. the SF36)

(d) Absence of "red flags" (e.g. infectious or malignant lesions, bowel or bladder paralysis)

(e) Age $\geq 18$ years

(f) Absence of absolute contraindications for active treatment (e.g. unfit for surgery, pregnancy, spine infection, and coagulation disorder)

(g) Absence of severe psychological disease and/or distress

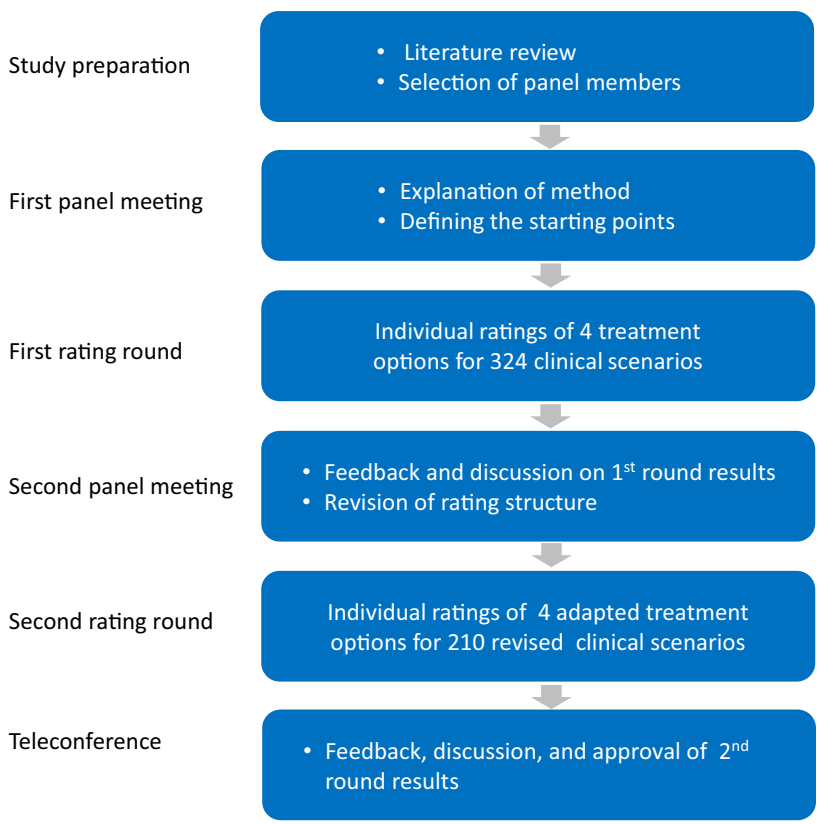

Fig. 1 Flow diagram of the panel study 
The panel acknowledged the importance of psychological aspects of chronic pain, but wished to focus on somatosensory aspects. For that reason, the psychological dimension of PPSS and its impact on treatment choice was not considered in this study.

Selected treatment options for the first round were conservative treatment, spinal cord stimulation, re-operation, and "specialised diagnostic evaluation" (including facet denervation, root blocks, and spinal endoscopy). The panel identified a number of variables that may be relevant to treatment choice: previous spinal surgery (decompression/fusion), onset of pain (remaining/recurrent), location of pain (leg/back/ mixed), type of pain (neuropathic/nociceptive/mixed), concordance of signs and symptoms with anatomic abnormalities (yes/no/uncertain), and age $(<50,50-70,>70$ years).

The panel extensively discussed the definitions of neuropathic and nociceptive pain to be used. It was agreed that the taxonomy of the International Association for the Study of Pain (IASP) is a good concept [36], but that its application in PPSS is sometimes problematic, and may confuse the appropriateness ratings. For that reason, it was decided to use the term neuropathic (like) pain in the ratings, thereby including a broader group of patients with neuropathic signs and symptoms than would fit within the IASP definition. This approximates more the reality of presentation of complaints of patients with PPSS. For reasons of brevity, the term neuropathic pain will be used throughout this manuscript.
By permutation of the clinical variables, a set of 324 mutually exclusive scenarios (unique patient profiles) was constructed. Using an electronic rating program, panellists individually assessed the appropriateness of the 4 treatment options for all 324 scenarios using a 9-point scale (reference values: $1=$ inappropriate, $5=$ uncertain, $9=$ appropriate). According to the RUAM definition, a treatment was considered appropriate if the expected benefits outweigh the expected negative consequences by a sufficient margin [29]. Panellists were instructed to take the clinical perspective as a starting point, and to disregard cost and reimbursement of treatments. The rating results were discussed during the second panel meeting (Paris, April 2017). Panellists received feedback on their own ratings in comparison with the anonymous results of their colleagues. The panel discussion led to a number of adaptations to the clinical variables, treatment options, and definitions. The final set included 1 variable with 2 categories, 3 variables with 3 categories, and 1 variable with 5 categories (Table 1), summing up to $\left(2^{1} * 3^{3} * 5^{1}=\right) 270$ scenarios. After exclusion of 60 scenarios that the panel considered to be unrealistic or falling beyond the scope of this study (for example nociceptive leg pain), 210 scenarios remained for which the appropriateness of treatments was assessed during the second round. Final recommendations were established and approved during a web conference (October 2017). An overview of clinical
Table 1 Overview of clinical variables and treatment options used for the construction of patient scenarios in the second rating round

\begin{tabular}{ll}
\hline Clinical variables & \\
Previous spinal surgery & (a) Non-instrumented \\
& (b) Instrumented/fusion \\
Onset of pain & (a) Remaining \\
(b) Recurrent \\
(c) New (other than initial pain) \\
(a) Predominantly leg \\
Location of pain & (b) Predominantly back \\
(c) Mixed \\
(a) Predominantly neuropathic (cf. DN4 $\geq 4$ ) \\
(b) Predominantly nociceptive \\
(c) Mixed \\
Anatomic abnormality & (a) Recurrent disc \\
(b) Pronounced scar tissue or iatrogenic lesion & (c) Spinal or foraminal stenosis \\
(d) Spinal instability \\
(e) None or not concordant with symptoms \\
(a) Conservative treatment \\
(includes physiotherapy, pharmacological therapy, rehabilitation \\
therapy, intensive pain program) \\
(b) Minimally invasive treatment \\
(may include interventional techniques such as selective nerve root \\
blocks, facet and sacroiliac joint infiltration/denervation, pulsed \\
radiofrequency and epidural injection) \\
(c) Neurostimulation (all types) \\
(d) Re-operation (all types)
\end{tabular}

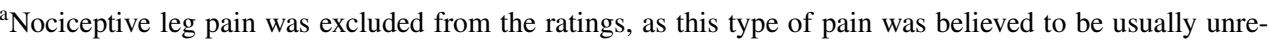
lated to previous spinal surgery 
variables and treatment options used in the second round is provided in Table 1.

\section{Classification of appropriateness and statistical analysis}

Similar to most RUAM studies, appropriateness of treatments was classified using the median panel score and extent of agreement between panellists [29]. The outcome was considered appropriate if the median score was between 7 and 9, and inappropriate if the median was between 1 and 3 , without disagreement between panellists. Disagreement was defined as the situation in which at least one-third of the panellists scored in each of the sections 1-3 and 7-9 [29]. All other outcomes were deemed "uncertain". Frequency tables and cross-tabulations were used to describe the appropriateness outcomes by treatment choice, clinical variables, and specialty. Multivariate logistic regression was used to analyse underlying patterns and to determine the internal consistency of the ratings. All statistical analyses were performed using IBM SPSS for Windows version 25.

\section{Results}

\section{Agreement and appropriateness}

For all indications together, disagreement after the second round was $8 \%$. Dispersion of opinions was highest for minimally invasive treatment and re-operation in patients with predominant back pain (disagreement 68 and 88\%, respectively). Appropriateness outcomes for the theoretical patient population are shown in Fig. 2.

Conservative treatment was considered appropriate for around two-thirds of cases. The choice for minimally

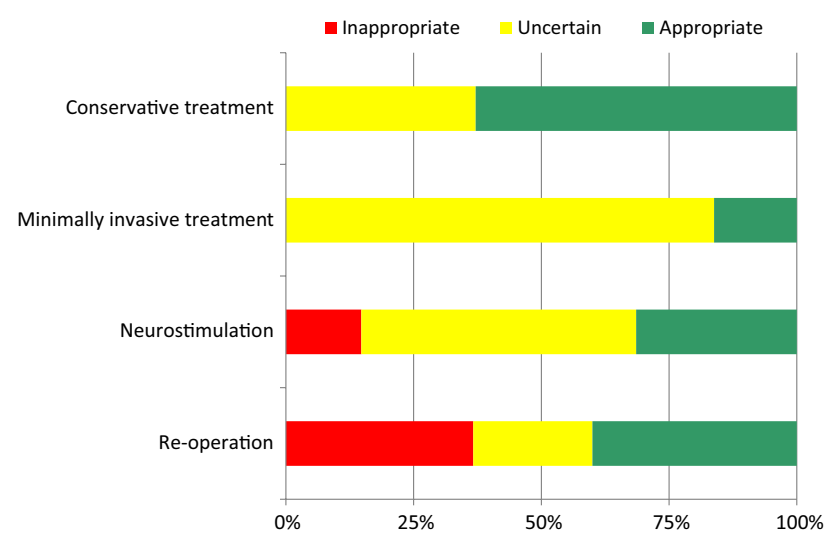

Fig. 2 Appropriateness of treatment; second round results. Percentage of the 210 clinical scenarios for which the panel outcome was appropriate, inappropriate, or uncertain invasive treatments showed the highest proportion of uncertainty $(84 \%)$. Inappropriate indications were seen for neurostimulation (15\%) and re-operation (37\%). The "rating behaviour" of individual panel members showed large variations: the proportion of ratings in the sections 1-3, 4-6, and $7-9$ ranged from 0 to $46 \%, 3$ to $65 \%$, and 15 to $65 \%$, respectively. However, differences in appropriateness outcomes across specialties were modest (Fig. 3). The difference between the mean median scores was at most 1.1 points on the 9-point scale.

The appropriateness of treatments by clinical variables is shown in Table 2 .

Evidence for anatomic abnormality appeared to be the most discriminative variable. Conservative treatment was considered appropriate for most patients with pronounced scar tissue or iatrogenic lesion and for those with no or inconclusive evidence for an anatomic abnormality. The same factors were obviously considered as a contraindication for re-operation. Spinal instability proved to be an important factor in favour of re-operation, and against minimally invasive treatment and neurostimulation. The presence of predominant leg pain was the strongest single factor in favour of neurostimulation, while the presence of predominant nociceptive (back) pain was the most important factor against this treatment option. The impact of the type of previous surgery was only significant for minimally invasive treatment: this treatment option was not considered appropriate for most patients with previous instrumented surgery and fusion. Onset of pain was most relevant for the choice of conservative treatment. The appropriateness of this option

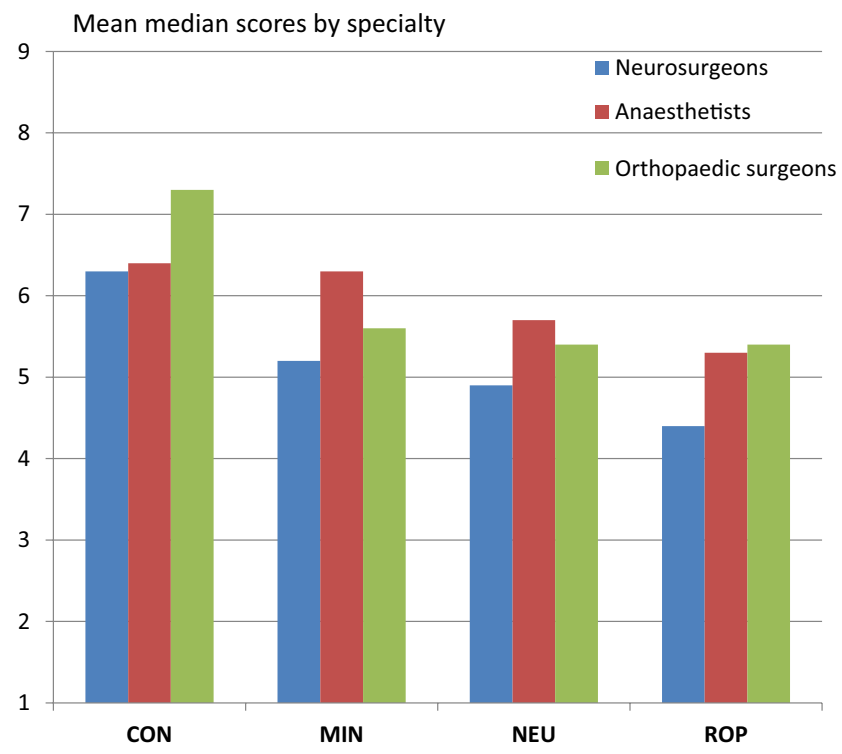

Fig. 3 Appropriateness of treatments by specialty; $\mathrm{CON}=$ conservative treatment, $\mathrm{MIN}=$ minimally invasive treatment, $\mathrm{NEU}=$ neurostimulation, $\mathrm{ROP}=$ re-operation 
Table 2 Appropriateness of treatments by clinical variables

\begin{tabular}{|c|c|c|c|c|c|}
\hline Variable & Category (\# scenarios) & $\mathrm{CON}(\%)$ & MIN (\%) & $\operatorname{NEU}(\%)$ & ROP $(\%)$ \\
\hline \multirow[t]{2}{*}{ Previous spinal surgery } & Non-instrumented (105) & 64 & 31 & 28 & 46 \\
\hline & Instrumented/fusion (105) & 62 & 2 & 35 & 34 \\
\hline \multirow[t]{3}{*}{ Onset of pain } & Remaining (70) & 44 & 11 & 30 & 41 \\
\hline & Recurrent (70) & 61 & 14 & 33 & 43 \\
\hline & New (70) & 83 & 23 & 31 & 36 \\
\hline \multirow[t]{3}{*}{ Location of pain } & Predominantly leg (30) & 50 & 17 & 73 & 50 \\
\hline & Predominantly back (90) & 75 & 16 & 9 & 24 \\
\hline & Mixed leg/back (90) & 56 & 17 & 40 & 52 \\
\hline \multirow[t]{3}{*}{ Type of pain } & Predominantly neuropathic (90) & 58 & 11 & 56 & 36 \\
\hline & Predominantly nociceptive (60) & 65 & 20 & $\mathbf{0}$ & 45 \\
\hline & Mixed (60) & 68 & 20 & 27 & 42 \\
\hline \multirow[t]{5}{*}{ Evidence for anatomic abnormality } & Recurrent disc (42) & 45 & 19 & 31 & 45 \\
\hline & Pronounced scar tissue or iatrogenic lesion (42) & 95 & 29 & 60 & $\mathbf{0}$ \\
\hline & Spinal/foraminal stenosis $(42)$ & 48 & 31 & 26 & 60 \\
\hline & Spinal instability $(42)$ & 29 & $\mathbf{0}$ & 2 & 95 \\
\hline & None/not concordant with symptoms (42) & 98 & 2 & 38 & $\mathbf{0}$ \\
\hline
\end{tabular}

Percentage of scenarios by subgroup for which the outcome was appropriate. Multiple treatment options can be appropriate for the same scenario Differences in appropriateness (appropriate versus inappropriate/uncertain) were analysed using the Pearson's Chi square test for categorical data. Bold figures indicate statistically significant differences with $p<0.001$

$\mathrm{CON}=$ conservative treatment, $\mathrm{MIN}=$ minimally invasive treatment, $\mathrm{NEU}=$ neurostimulation, $\mathrm{ROP}=$ re-operation

was substantially higher in patients with new pain, i.e. different from the type of pain for which the initial surgery took place.

Logistic regression analysis, with the outcome appropriate (yes/no) as the dependent variable and including all clinical variables as explanatory factors, confirmed the appropriateness patterns of the 4 treatment options, with predictive values for the statistical models varying between 83 and $94 \%$ at a cut-off value of 0.5 . Appropriateness outcomes were highly specific. In $48 \%$ of the scenarios, only one of the treatment options was appropriate, and in another 39\%, at most two options were appropriate. Principal appropriateness patterns are shown in Fig. 4. Detailed tables are provided in "Appendix 1".

\section{Discussion}

Due to the heterogeneity of the patient population and the variety of available treatment modalities, the management of PPSS requires an individualised approach, taking into consideration both physical and psychological aspects. This study focused on the somatosensory dimension of treatment choice. The RUAM proved to be helpful in identifying key variables from the perspective of daily clinical practice. Moreover, opinions on the appropriateness of treatments for 210 distinct patient profiles were remarkably in line across the specialties involved (Fig. 3). This is deviant from other RUAM studies that have shown a significant impact of panellist discipline on the ratings [30]. Furthermore, the appropriateness outcomes tended to be highly specific as in 48 and $87 \%$ of scenarios exclusively one or maximally two treatments were considered appropriate. The results of regression analysis support the internal consistency of the panel data.

\section{Comparison with guidelines and algorithms}

Evidence for anatomic abnormality proved to be the most discriminative variable in relation to the appropriateness of treatments. The absence of an anatomic abnormality or discordance with symptoms clearly and logically rules out surgical intervention, including minimally invasive procedures. Similar results were seen for patients with pronounced scar tissue or an iatrogenic lesion, with the difference that minimally invasive treatments may sometimes be an option here (Fig. 3). Available guidelines and algorithms do not explicitly give recommendations on scar tissue and iatrogenic lesion [6, 23-27]. However, there is general agreement in the surgical community that an already partially or completely damaged nerve or nerve root causing chronic neuropathic pain cannot be restored with any kind of surgery, and symptomatic pain therapy in a multidisciplinary setting is required $[37,38]$. For patients with spinal instability, re-operation is the most appropriate option. Conservative treatment in these patients may also be appropriate, (particularly) if the pain is different from the original pain for which 


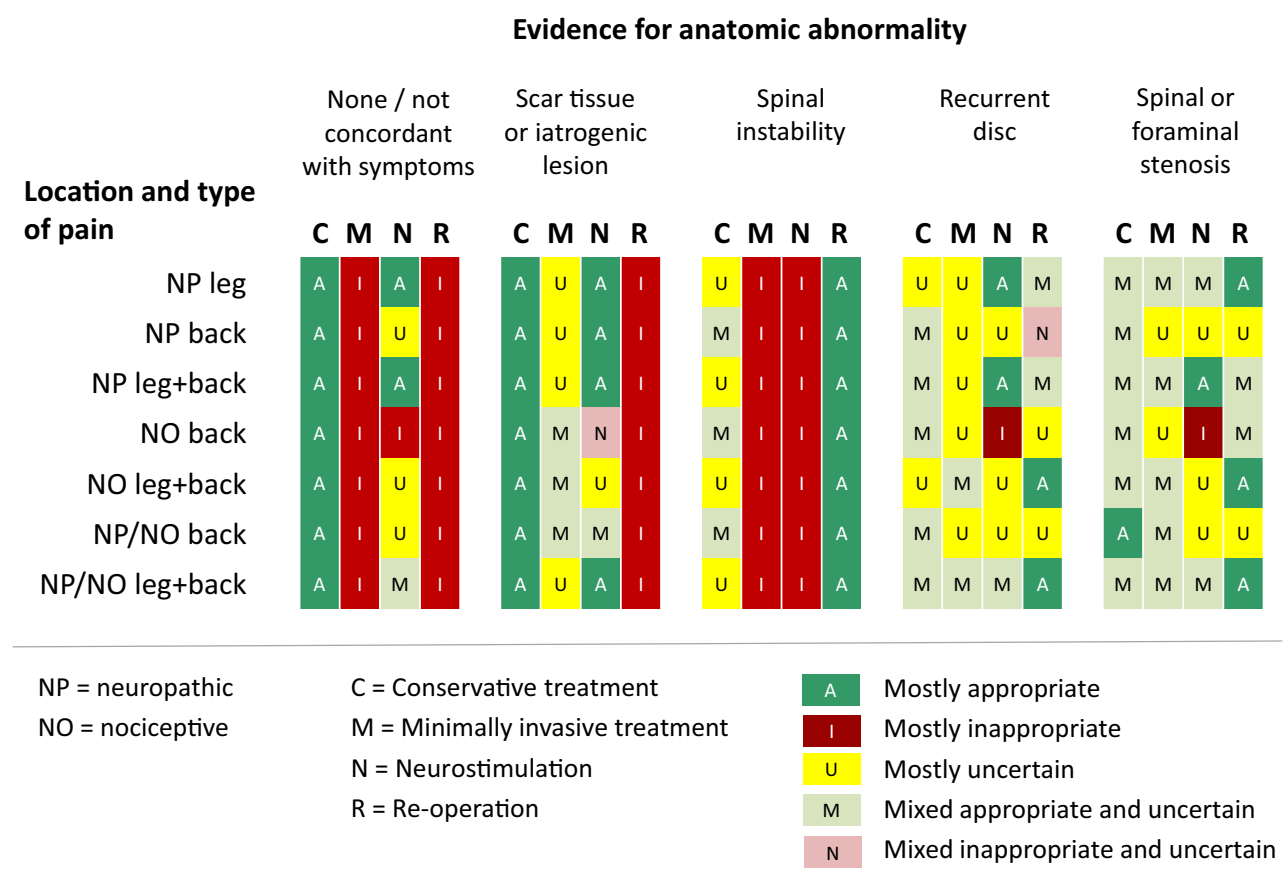

Fig. 4 Main appropriateness patterns. Summarised panel outcomes by key variables

previous spinal surgery took place (see "Appendix 1"). Reoperation was considered an appropriate option for most patients with a recurrent disc herniation or spinal/foraminal stenosis, and having predominant leg or mixed leg/back pain (Table 2, "Appendix 1"). Most currently available guidelines and algorithms do either not mention, or are not very specific on the indications for re-operation [6,23-25]. The algorithm by Van Buyten and Linderoth is close to our findings in this respect, as it considers re-operation indicated in patients with (recurrent) disc herniation and leg pain prevailing over back pain [27]. The algorithm suggested by Rigoard and Assaker is also largely in line with our recommendations, albeit that their specification of the related type of symptoms is different ("mixed back pain" or "exclusive/predominant axial back pain") [26]. According to the panel, neurostimulation is most appropriate in patients with predominant neuropathic leg or mixed leg/back pain, and without clear surgical indications such as spinal instability. This is in accordance with the inclusion criteria of some, but not all RCTs that have studied spinal cord stimulation for "failed back surgery syndrome" [39, 40], albeit that different terms have been used such as "radicular pain" or "neuropathic pain of radicular origin" $[39,40]$. The recommendations are also largely in line with the guidelines and algorithms in which neurostimulation was mentioned [6, 23-27]. Neurostimulation was also considered appropriate in the case of scar tissue or a iatrogenic lesion (Table 2), mostly in patients with a neuropathic leg pain component, but also for patients with exclusively neuropathic or mixed back pain (Fig. 4). The efficacy of SCS for PPSS patients with predominant low back pain is currently under study [41]. Minimally invasive treatments showed some specific indications for patients with (mostly) back or mixed leg/back pain after non-instrumented previous spinal surgery (Fig. 4, "Appendix 1"). Some guidelines and algorithms advise selective root blocks, radiofrequency, and epidural injections as a first (diagnostic) step in specific situations (e.g. suspected facet joint syndrome) [6, 26]. The overall panel recommendations are summarised in Table 3.

\section{Strengths and limitations}

Although the use of detailed clinical scenarios and the involvement of different specialties may be considered as strong points of this study, it still is a first step towards an individualised and multidisciplinary approach of managing PPSS.

The panel consisted of 3 different specialities, but there are many other disciplines that are involved in the management of persisting pain after spine surgery, and that all could have had a significant contribution to this project. However, the number of participants had to be limited to allow everyone to be involved in the group discussion. In addition, to be able to detect potential differences between specialities, a minimum number per specialty was needed. For these reasons, the panel was restricted to the primary decision-makers from both the spine and pain perspectives.

Although a variety of patient scenarios was used, the recommendations relate to a theoretical population and the applicability of the clinical factors and the distribution of scenarios need to be determined in daily practice. For 
Table 3 Summarised panel recommendations

Usually appropriate in patients with:

Usually not appropriate in patients with:

Conservative treatment $\quad \begin{aligned} & \text { No evidence of anatomic abnormalities or not concordant with symp- } \\ & \text { toms } \\ & \text { Scar tissue or iatrogenic lesion }\end{aligned}$

Minimally invasive treatment Patients with recurrent disc, spinal/foraminal stenosis, scar tissue or iatrogenic lesion after non-instrumented previous surgery, having back or mixed leg/back pain

Neurostimulation

Neuropathic leg/back pain without clear indications for re-operation

Neuropathic leg/back pain due to pronounced scar tissue or iatrogenic lesion

Re-operation

Recurrent disc, spinal or foraminal stenosis, in the presence of symptoms concordant with imaging

Spinal instability

No evidence of anatomic abnormalities or not concordant with symptoms

Exclusively nociceptive pain

Spinal instability

Scar tissue or iatrogenic lesion

No evidence of anatomic abnormalities or not concordant with symptoms reasons of practicability, a set of relatively simple variables without extensive definition was chosen. As was also noticed during the panel discussions, some of these may need further refinement. This is particularly true for the concept of neuropathic (versus nociceptive or mechanical) pain for which there is currently much debate on its precise nature $[14,42-45]$ and role in the diagnostic evaluation and treatment choice for patients with PPSS [12-14, 46, 47]. Further research may also consider the inclusion of additional somatic variables, potentially relevant to treatment choice, such as sagittal balance $[15,16]$.

The focus of this study was on somatosensory aspects which is surely an important limitation. Psychological and social aspects are very important in the management of PPSS, but including this dimension would have substantially increased the complexity and extensiveness of the study. This study should therefore be considered as a foundation on which further refinements can be made.

\section{Conclusions}

The lack of coherence in the management of PPSS and large practice variations urge consensus development from a multidisciplinary perspective. Using the RUAM, an international panel of pain and spine specialists established a set of appropriateness criteria for conservative, minimally invasive, and surgical interventions. These could be a starting point to improve consistency of care, to further design more specific studies, and to reduce undesirable practice variations. The study outcomes, both the summarised recommendations and look-up tables, may be used for reflection on individual clinical decisions, and also for discussion in educational settings. However, validity and applicability of the panel recommendations in daily clinical practice need further study.

Acknowledgement The authors thank Sofie Vets from Ismar Healthcare for her editorial assistance during the manuscript preparation.
Funding The study was funded by Medtronic International Trading Sàrl.

\section{Compliance with ethical standards}

Conflict of interest Panellists were financially compensated for their time and reimbursed for travel and hotel costs by the funder. Other COI declarations: VT has received consulting fees from Medtronic and EISAI in the form of honoraria for lectures or attendances at advisory boards/steering committees over the last 5 years. His Department has received research funding from Deutsche Forschungsgemeinschaft, Bundesministerium für Bildung und Forschung, Kreitzstiftung, Medtronic Europe, and Abbott over the last 5 years. SE has received consulting fees from Medtronic, Boston Scientific, Abbott, Mainstay Medical and Saluda Medical in the form of honoraria for lectures or attendances at advisory boards/steering committees over the last 5 years. His Department has received research funding from the $\mathrm{Na}$ tional Institute of Health Research UK, Medtronic Europe, and Nevro. $\mathrm{JF}$ has received consultancy fees/honoraria from Medronic, Medacta, Relievant, Zimmer, Paradigm, Baxter, Globus medical, EOs Imaging, EItgeistlich and Safe Orthopedics, royalties from Medacta, OHST and Medtronic, and research grants from Medtronic, Relievant, Baxter, Zimmer, Geistlich, Eos Imaging and Paradigm Spine. FH has received honoraria as a consultant for ABBOTT, Medtronic and Grunenthal. PR has received grants and personal fees from Medtronic, Abbott and Boston Sci. RA has received honoraria for lectures/courses from Medtronic and DePuy Synthes, royalties from Medtronic, and advisory board honoraria from SpineGuard. AG-R has received honoraria for lectures/ courses from Medtronic and Stryker. MM has received speaker fees and independent research grants from Medtronic and Nevro. LM received consultancy fees from Medtronic. His institute received fellowship grants from Medtronic and Spinevision, research grants from Research Foundation Flanders (FWO), KU Leuven C2 grant and KU Leuven Medtronic Educational Chair. CP is consultant for Medtronic. PT holds consultant agreements with Medtronic and Abbott. HJS has received honoraria from Medtronic for advice to the design of the study and data analysis. MLG, JAA, NQ, DR, KVB, CVL, and BZ declare that they have no other conflict of interest.

Open Access This article is distributed under the terms of the Creative Commons Attribution 4.0 International License (http://creativeco mmons.org/licenses/by/4.0/), which permits unrestricted use, distribution, and reproduction in any medium, provided you give appropriate credit to the original author(s) and the source, provide a link to the Creative Commons license, and indicate if changes were made. 


\section{Appendix 1: Appropriateness by clinical variables}

See Tables 4, 5, 6, 7 and 8 .

Table 4 Appropriateness of treatments for patients with anatomic evidence of recurrent disc

\begin{tabular}{|c|c|c|c|c|c|c|c|}
\hline \multirow[b]{2}{*}{$\begin{array}{l}\text { Previous } \\
\text { Surgery }\end{array}$} & \multirow[b]{2}{*}{$\begin{array}{l}\text { Onset } \\
\text { of pain }\end{array}$} & \multirow[b]{2}{*}{$\begin{array}{l}\text { Location } \\
\text { of pain }\end{array}$} & \multirow[b]{2}{*}{$\begin{array}{l}\text { Type } \\
\text { of pain }\end{array}$} & \multicolumn{4}{|c|}{ Treatment } \\
\hline & & & & CON & MIN & NEU & ROP \\
\hline Non-instrumented & Remaining & Leg & Neuropathic & $\mathrm{U}$ & $\mathrm{U}$ & A & A \\
\hline Non-instrumented & Remaining & Back & Neuropathic & $\mathrm{U}$ & $U$ & $\mathrm{U}$ & $U$ \\
\hline Non-instrumented & Remaining & Back & Mixed & $U$ & U & $\mathrm{U}$ & $\mathrm{U}$ \\
\hline Non-instrumented & Remaining & Back & Nociceptive & $U$ & $\mathrm{U}$ & I & U \\
\hline Non-instrumented & Remaining & Mixed & Neuropathic & $U$ & $\mathrm{U}$ & A & $U$ \\
\hline Non-instrumented & Remaining & Mixed & Mixed & $\bar{U}$ & $\bar{A}$ & $\bar{A}$ & $\bar{A}$ \\
\hline Non-instrumented & Remaining & Mixed & Nociceptive & $U$ & A & I & A \\
\hline Non-instrumented & Recurrent & Leg & Neuropathic & $\mathrm{U}$ & A & A & A \\
\hline Non-instrumented & Recurrent & Back & Neuropathic & A & U & $U$ & U \\
\hline Non-instrumented & Recurrent & Back & Mixed & A & $\mathrm{U}$ & $\mathrm{U}$ & $\mathrm{U}$ \\
\hline Non-instrumented & Recurrent & Back & Nociceptive & A & $\mathrm{U}$ & I & $\mathrm{U}$ \\
\hline Non-instrumented & Recurrent & Mixed & Neuropathic & A & $U$ & A & A \\
\hline Non-instrumented & Recurrent & Mixed & Mixed & $\mathrm{A}$ & $\bar{A}$ & $\mathrm{U}$ & A \\
\hline Non-instrumented & Recurrent & Mixed & Nociceptive & $A$ & A & $U$ & A \\
\hline Non-instrumented & New & Leg & Neuropathic & $\mathrm{U}$ & $\mathrm{U}$ & $\mathrm{U}$ & A \\
\hline Non-instrumented & New & Back & Neuropathic & $\mathrm{U}$ & A & $U$ & $\mathrm{U}$ \\
\hline Non-instrumented & New & Back & Mixed & A & A & $\mathrm{U}$ & A \\
\hline Non-instrumented & New & Back & Nociceptive & $\bar{A}$ & A & I & $U$ \\
\hline Non-instrumented & New & Mixed & Neuropathic & $\mathrm{U}$ & $\mathrm{U}$ & A & A \\
\hline Non-instrumented & New & Mixed & Mixed & A & $\mathrm{U}$ & U & A \\
\hline Non-instrumented & New & Mixed & Nociceptive & $U$ & $U$ & $U$ & A \\
\hline
\end{tabular}

\begin{tabular}{|l|l|l|l|}
\hline Instrumented/fusion & Remaining & Leg & Neuropathic \\
\hline Instrumented/fusion & Remaining & Back & Neuropathic \\
\hline Instrumented/fusion & Remaining & Back & Mixed \\
\hline Instrumented/fusion & Remaining & Back & Nociceptive \\
\hline Instrumented/fusion & Remaining & Mixed & Neuropathic \\
\hline Instrumented/fusion & Remaining & Mixed & Mixed \\
\hline Instrumented/fusion & Remaining & Mixed & Nociceptive \\
\hline Instrumented/fusion & Recurrent & Leg & Neuropathic \\
\hline Instrumented/fusion & Recurrent & Back & Neuropathic \\
\hline Instrumented/fusion & Recurrent & Back & Mixed \\
\hline Instrumented/fusion & Recurrent & Back & Nociceptive \\
\hline Instrumented/fusion & Recurrent & Mixed & Neuropathic \\
\hline Instrumented/fusion & Recurrent & Mixed & Mixed \\
\hline Instrumented/fusion & Recurrent & Mixed & Nociceptive \\
\hline Instrumented/fusion & New & Leg & Neuropathic \\
\hline Instrumented/fusion & New & Back & Neuropathic \\
\hline Instrumented/fusion & New & Back & Mixed \\
\hline Instrumented/fusion & New & Back & Nociceptive \\
\hline Instrumented/fusion & New & Mixed & Neuropathic \\
\hline Instrumented/fusion & New & Mixed \\
\hline Instrumented/fusion & New & Mixed & Nociceptive \\
\hline
\end{tabular}

\begin{tabular}{|c|c|c|c|}
\hline$U$ & $U$ & $A$ & $U$ \\
\hline$A$ & $U$ & $U$ & $U$ \\
\hline$A$ & $U$ & $U$ & $U$ \\
\hline$A$ & $U$ & $I$ & $U$ \\
\hline$U$ & $U$ & $A$ & $A$ \\
\hline$U$ & $U$ & $U$ & $A$ \\
\hline$U$ & $U$ & $U$ & $A$ \\
\hline$U$ & $U$ & $A$ & $A$ \\
\hline$U$ & $U$ & $U$ & $U$ \\
\hline$U$ & $U$ & $U$ & $U$ \\
\hline$U$ & $U$ & $I$ & $U$ \\
\hline$A$ & $U$ & $A$ & $U$ \\
\hline$U$ & $U$ & $U$ & $U$ \\
\hline$U$ & $U$ & $U$ & $A$ \\
\hline$A$ & $U$ & $A$ & $U$ \\
\hline$A$ & $U$ & $U$ & $I$ \\
\hline$A$ & $U$ & $U$ & $U$ \\
\hline$A$ & $U$ & $U$ & $U$ \\
\hline$A$ & $U$ & $A$ & $U$ \\
\hline$A$ & $U$ & $A$ & $A$ \\
\hline$U$ & $U$ & $U$ & $A$ \\
\hline & & & \\
\hline
\end{tabular}

$\mathrm{CON}=$ conservative treatment

MIN = minimally invasive treatment

$\mathrm{NEU}=$ neurostimulation

$\mathrm{ROP}=$ re-operation 
Table 5 Appropriateness of treatments for patients with anatomic evidence of pronounced scar tissue or iatrogenic lesion

\begin{tabular}{|c|c|c|c|}
\hline $\begin{array}{l}\text { Previous } \\
\text { Surgery }\end{array}$ & $\begin{array}{l}\text { Onset } \\
\text { of pain }\end{array}$ & $\begin{array}{l}\text { Location } \\
\text { of pain }\end{array}$ & $\begin{array}{l}\text { Type } \\
\text { of pain }\end{array}$ \\
\hline Non-instrumented & Remaining & Leg & Neuropathic \\
\hline Non-instrumented & Remaining & Back & Neuropathic \\
\hline Non-instrumented & Remaining & Back & Mixed \\
\hline Non-instrumented & Remaining & Back & Nociceptive \\
\hline Non-instrumented & Remaining & Mixed & Neuropathic \\
\hline Non-instrumented & Remaining & Mixed & Mixed \\
\hline Non-instrumented & Remaining & Mixed & Nociceptive \\
\hline Non-instrumented & Recurrent & Leg & Neuropathic \\
\hline Non-instrumented & Recurrent & Back & Neuropathic \\
\hline Non-instrumented & Recurrent & Back & Mixed \\
\hline Non-instrumented & Recurrent & Back & Nociceptive \\
\hline Non-instrumented & Recurrent & Mixed & Neuropathic \\
\hline Non-instrumented & Recurrent & Mixed & Mixed \\
\hline Non-instrumented & Recurrent & Mixed & Nociceptive \\
\hline Non-instrumented & New & Leg & Neuropathic \\
\hline Non-instrumented & New & Back & Neuropathic \\
\hline Non-instrumented & New & Back & Mixed \\
\hline Non-instrumented & New & Back & Nociceptive \\
\hline Non-instrumented & New & Mixed & Neuropathic \\
\hline Non-instrumented & New & Mixed & Mixed \\
\hline Non-instrumented & New & Mixed & Nociceptive \\
\hline Instrumented/fusion & Remaining & Leg & Neuropathic \\
\hline Instrumented/fusion & Remaining & Back & Neuropathic \\
\hline Instrumented/fusion & Remaining & Back & Mixed \\
\hline Instrumented/fusion & Remaining & Back & Nociceptive \\
\hline Instrumented/fusion & Remaining & Mixed & Neuropathic \\
\hline Instrumented/fusion & Remaining & Mixed & Mixed \\
\hline Instrumented/fusion & Remaining & Mixed & Nociceptive \\
\hline Instrumented/fusion & Recurrent & Leg & Neuropathic \\
\hline Instrumented/fusion & Recurrent & Back & Neuropathic \\
\hline Instrumented/fusion & Recurrent & Back & Mixed \\
\hline Instrumented/fusion & Recurrent & Back & Nociceptive \\
\hline Instrumented/fusion & Recurrent & Mixed & Neuropathic \\
\hline Instrumented/fusion & Recurrent & Mixed & Mixed \\
\hline Instrumented/fusion & Recurrent & Mixed & Nociceptive \\
\hline Instrumented/fusion & New & Leg & Neuropathic \\
\hline Instrumented/fusion & New & Back & Neuropathic \\
\hline Instrumented/fusion & New & Back & Mixed \\
\hline Instrumented/fusion & New & Back & Nociceptive \\
\hline Instrumented/fusion & New & Mixed & Neuropathic \\
\hline Instrumented/fusion & New & Mixed & Mixed \\
\hline Instrumented/fusion & New & Mixed & Nociceptive \\
\hline
\end{tabular}

Treatment

CON MIN NEU ROP

\begin{tabular}{|c|c|c|c|}
\hline A & $U$ & A & I \\
\hline A & $U$ & $U$ & I \\
\hline $\mathrm{A}$ & A & $\mathrm{U}$ & I \\
\hline A & A & I & I \\
\hline A & $U$ & A & I \\
\hline A & $\mathrm{U}$ & $\mathrm{A}$ & I \\
\hline A & A & $U$ & I \\
\hline A & $U$ & A & U \\
\hline$A$ & A & A & I \\
\hline A & A & A & U \\
\hline A & A & $U$ & I \\
\hline A & $U$ & A & I \\
\hline A & $\mathrm{U}$ & A & I \\
\hline A & $U$ & $U$ & U \\
\hline A & $\mathrm{A}$ & A & I \\
\hline A & $U$ & A & I \\
\hline A & A & $U$ & 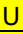 \\
\hline$A$ & A & I & $\bar{U}$ \\
\hline A & $U$ & A & I \\
\hline A & $A$ & $\mathrm{~A}$ & I \\
\hline A & A & $\mathrm{U}$ & $U$ \\
\hline
\end{tabular}

CON = conservative treatment

MIN = minimally invasive treatment

$\mathrm{NEU}=$ neurostimulation

\begin{tabular}{|c|c|c|c|}
\hline A & $U$ & A & I \\
\hline$A$ & U & $A$ & I \\
\hline $\bar{A}$ & $\mathrm{U}$ & $\bar{U}$ & I \\
\hline A & $U$ & $\mathrm{U}$ & I \\
\hline $\mathrm{U}$ & $\mathrm{U}$ & $\mathrm{A}$ & I \\
\hline$U$ & U & $A$ & $U$ \\
\hline$A$ & U & U & $\mathrm{U}$ \\
\hline A & U & $A$ & I \\
\hline$A$ & $\mathrm{U}$ & $A$ & I \\
\hline $\bar{A}$ & $\mathrm{U}$ & $U$ & I \\
\hline$A$ & $\mathrm{U}$ & $\mathrm{U}$ & I \\
\hline$A$ & U & $A$ & I \\
\hline A & U & A & I \\
\hline A & $U$ & $\mathrm{U}$ & I \\
\hline $\bar{A}$ & $\bar{U}$ & $\bar{A}$ & I \\
\hline $\mathrm{A}$ & $\mathrm{U}$ & A & I \\
\hline $\bar{A}$ & $\mathrm{U}$ & $\bar{A}$ & I \\
\hline A & $A$ & U & I \\
\hline$A$ & U & $A$ & I \\
\hline A & U & A & I \\
\hline A & $\mathrm{U}$ & $\mathrm{U}$ & I \\
\hline
\end{tabular}

$\mathrm{ROP}=$ re-operation

Appropriate

Uncertain

Inappropriate 
Table 6 Appropriateness of treatments for patients with anatomic evidence of spinal/foraminal stenosis

\begin{tabular}{|c|c|c|c|c|c|c|c|}
\hline \multirow[b]{2}{*}{$\begin{array}{l}\text { Previous } \\
\text { Surgery }\end{array}$} & \multirow[b]{2}{*}{$\begin{array}{l}\text { Onset } \\
\text { of pain }\end{array}$} & \multirow[b]{2}{*}{$\begin{array}{l}\text { Location } \\
\text { of pain }\end{array}$} & \multirow[b]{2}{*}{$\begin{array}{l}\text { Type } \\
\text { of pain }\end{array}$} & \multicolumn{4}{|c|}{ Treatment } \\
\hline & & & & CON & MIN & NEU & ROP \\
\hline Non-instrumented & Remaining & Leg & Neuropathic & $\mathrm{U}$ & A & $\mathrm{U}$ & $\bar{A}$ \\
\hline Non-instrumented & Remaining & Back & Neuropathic & $\mathrm{U}$ & $\mathrm{U}$ & $\mathrm{U}$ & $\mathrm{U}$ \\
\hline Non-instrumented & Remaining & Back & Mixed & A & A & $U$ & $U$ \\
\hline Non-instrumented & Remaining & Back & Nociceptive & $U$ & U & I & A \\
\hline Non-instrumented & Remaining & Mixed & Neuropathic & $\mathrm{U}$ & $\mathrm{U}$ & $\mathrm{U}$ & A \\
\hline Non-instrumented & Remaining & Mixed & Mixed & $\mathrm{U}$ & $\mathrm{U}$ & $U$ & A \\
\hline Non-instrumented & Remaining & Mixed & Nociceptive & $\mathrm{U}$ & $\mathrm{U}$ & $U$ & A \\
\hline Non-instrumented & Recurrent & Leg & Neuropathic & $\mathrm{U}$ & A & A & A \\
\hline Non-instrumented & Recurrent & Back & Neuropathic & $\mathrm{U}$ & $U$ & $U$ & $U$ \\
\hline Non-instrumented & Recurrent & Back & Mixed & $\mathrm{U}$ & $\mathrm{U}$ & $U$ & $\mathrm{~A}$ \\
\hline Non-instrumented & Recurrent & Back & Nociceptive & $\mathrm{U}$ & U & I & A \\
\hline Non-instrumented & Recurrent & Mixed & Neuropathic & A & A & A & A \\
\hline Non-instrumented & Recurrent & Mixed & Mixed & A & $\mathrm{A}$ & A & A \\
\hline Non-instrumented & Recurrent & Mixed & Nociceptive & A & A & $U$ & A \\
\hline Non-instrumented & New & Leg & Neuropathic & A & A & $U$ & $\mathrm{~A}$ \\
\hline Non-instrumented & New & Back & Neuropathic & A & A & $\mathrm{U}$ & $\mathrm{U}$ \\
\hline Non-instrumented & New & Back & Mixed & A & $\bar{A}$ & $\mathrm{U}$ & $\mathrm{U}$ \\
\hline Non-instrumented & New & Back & Nociceptive & A & $\mathrm{U}$ & I & $A$ \\
\hline Non-instrumented & New & Mixed & Neuropathic & $\mathrm{U}$ & A & A & $U$ \\
\hline Non-instrumented & New & Mixed & Mixed & $\mathrm{U}$ & $\bar{A}$ & $\mathrm{U}$ & $\bar{A}$ \\
\hline Non-instrumented & New & Mixed & Nociceptive & $\mathrm{U}$ & A & $U$ & A \\
\hline
\end{tabular}

\begin{tabular}{|l|l|l|l|}
\hline Instrumented/fusion & Remaining & Leg & Neuropathic \\
\hline Instrumented/fusion & Remaining & Back & Neuropathic \\
\hline Instrumented/fusion & Remaining & Back & Mixed \\
\hline Instrumented/fusion & Remaining & Back & Nociceptive \\
\hline Instrumented/fusion & Remaining & Mixed & Neuropathic \\
\hline Instrumented/fusion & Remaining & Mixed & Mixed \\
\hline Instrumented/fusion & Remaining & Mixed & Nociceptive \\
\hline Instrumented/fusion & Recurrent & Leg & Neuropathic \\
\hline Instrumented/fusion & Recurrent & Back & Neuropathic \\
\hline Instrumented/fusion & Recurrent & Back & Mixed \\
\hline Instrumented/fusion & Recurrent & Back & Nociceptive \\
\hline Instrumented/fusion & Recurrent & Mixed & Neuropathic \\
\hline Instrumented/fusion & Recurrent & Mixed & Mixed \\
\hline Instrumented/fusion & Recurrent & Mixed & Nociceptive \\
\hline Instrumented/fusion & New & Leg & Neuropathic \\
\hline Instrumented/fusion & New & Back & Neuropathic \\
\hline Instrumented/fusion & New & Back & Mixed \\
\hline Instrumented/fusion & New & Back & Nociceptive \\
\hline Instrumented/fusion & New & Mixed & Neuropathic \\
\hline Instrumented/fusion & New & Mixed & Mixed \\
\hline Instrumented/fusion & New & Nociceptive \\
\hline
\end{tabular}

\begin{tabular}{|c|c|c|c|}
\hline$U$ & $U$ & $A$ & $A$ \\
\hline$U$ & $U$ & $U$ & $U$ \\
\hline$A$ & $U$ & $U$ & $U$ \\
\hline$A$ & $U$ & $I$ & $U$ \\
\hline$U$ & $U$ & $A$ & $A$ \\
\hline$U$ & $U$ & $A$ & $A$ \\
\hline$U$ & $U$ & $U$ & $A$ \\
\hline$U$ & $U$ & $A$ & $A$ \\
\hline$A$ & $U$ & $U$ & $U$ \\
\hline$A$ & $U$ & $U$ & $U$ \\
\hline$A$ & $U$ & $I$ & $U$ \\
\hline$U$ & $U$ & $A$ & $A$ \\
\hline$U$ & $U$ & $U$ & $A$ \\
\hline$U$ & $U$ & $U$ & $A$ \\
\hline$A$ & $U$ & $A$ & $U$ \\
\hline$A$ & $U$ & $U$ & $U$ \\
\hline$A$ & $U$ & $U$ & $U$ \\
\hline$A$ & $U$ & $I$ & $U$ \\
\hline$A$ & $U$ & $A$ & $U$ \\
\hline$A$ & $A$ & $U$ & $A$ \\
\hline$A$ & $U$ & $U$ & $A$ \\
\hline
\end{tabular}

$\mathrm{CON}=$ conservative treatment

MIN = minimally invasive treatment

$\mathrm{NEU}=$ neurostimulation

ROP $=$ re-operation 
Table 7 Appropriateness of treatments for patients with anatomic evidence of spinal instability

\begin{tabular}{|c|c|c|c|c|c|c|c|}
\hline \multirow[b]{2}{*}{$\begin{array}{l}\text { Previous } \\
\text { Surgery }\end{array}$} & \multirow[b]{2}{*}{$\begin{array}{l}\text { Onset } \\
\text { of pain }\end{array}$} & \multirow[b]{2}{*}{$\begin{array}{l}\text { Location } \\
\text { of pain }\end{array}$} & \multirow[b]{2}{*}{$\begin{array}{l}\text { Type } \\
\text { of pain }\end{array}$} & \multicolumn{4}{|c|}{ Treatment } \\
\hline & & & & CON & MIN & NEU & ROP \\
\hline Non-instrumented & Remaining & Leg & Neuropathic & $\mathrm{U}$ & $\mathrm{U}$ & I & A \\
\hline Non-instrumented & Remaining & Back & Neuropathic & $\mathrm{U}$ & $\mathrm{U}$ & I & A \\
\hline Non-instrumented & Remaining & Back & Mixed & $\mathrm{U}$ & $\mathrm{U}$ & I & A \\
\hline Non-instrumented & Remaining & Back & Nociceptive & $\mathrm{U}$ & $\mathrm{U}$ & I & A \\
\hline Non-instrumented & Remaining & Mixed & Neuropathic & $\mathrm{U}$ & $\mathrm{U}$ & $\mathrm{U}$ & A \\
\hline Non-instrumented & Remaining & Mixed & Mixed & $\mathrm{U}$ & $\mathrm{U}$ & $U$ & A \\
\hline Non-instrumented & Remaining & Mixed & Nociceptive & $\mathrm{U}$ & $\mathrm{U}$ & I & A \\
\hline Non-instrumented & Recurrent & Leg & Neuropathic & $\mathrm{U}$ & $\mathrm{U}$ & $u$ & A \\
\hline Non-instrumented & Recurrent & Back & Neuropathic & $\mathrm{U}$ & $U$ & U & A \\
\hline Non-instrumented & Recurrent & Back & Mixed & A & $\mathrm{U}$ & $U$ & A \\
\hline Non-instrumented & Recurrent & Back & Nociceptive & A & U & $\mathrm{U}$ & A \\
\hline Non-instrumented & Recurrent & Mixed & Neuropathic & $\mathrm{U}$ & $\mathrm{U}$ & $U$ & A \\
\hline Non-instrumented & Recurrent & Mixed & Mixed & $\mathrm{U}$ & $\mathrm{U}$ & $\mathrm{U}$ & A \\
\hline Non-instrumented & Recurrent & Mixed & Nociceptive & $\mathrm{U}$ & $\mathrm{U}$ & $U$ & A \\
\hline Non-instrumented & New & Leg & Neuropathic & A & U & $U$ & A \\
\hline Non-instrumented & New & Back & Neuropathic & A & $\mathrm{U}$ & $\mathrm{U}$ & A \\
\hline Non-instrumented & New & Back & Mixed & A & $\mathrm{U}$ & $\mathrm{U}$ & $\mathrm{A}$ \\
\hline Non-instrumented & New & Back & Nociceptive & $\bar{A}$ & $\mathrm{U}$ & I & $\bar{A}$ \\
\hline Non-instrumented & New & Mixed & Neuropathic & A & $\mathrm{U}$ & $\mathrm{U}$ & A \\
\hline Non-instrumented & New & Mixed & Mixed & A & $\mathrm{U}$ & $U$ & $\bar{A}$ \\
\hline Non-instrumented & New & Mixed & Nociceptive & A & U & $\mathrm{U}$ & A \\
\hline
\end{tabular}

\begin{tabular}{|l|l|l|l|}
\hline Instrumented/fusion & Remaining & Leg & Neuropathic \\
\hline Instrumented/fusion & Remaining & Back & Neuropathic \\
\hline Instrumented/fusion & Remaining & Back & Mixed \\
\hline Instrumented/fusion & Remaining & Back & Nociceptive \\
\hline Instrumented/fusion & Remaining & Mixed & Neuropathic \\
\hline Instrumented/fusion & Remaining & Mixed & Mixed \\
\hline Instrumented/fusion & Remaining & Mixed & Nociceptive \\
\hline Instrumented/fusion & Recurrent & Leg & Neuropathic \\
\hline Instrumented/fusion & Recurrent & Back & Neuropathic \\
\hline Instrumented/fusion & Recurrent & Back & Mixed \\
\hline Instrumented/fusion & Recurrent & Back & Nociceptive \\
\hline Instrumented/fusion & Recurrent & Mixed & Neuropathic \\
\hline Instrumented/fusion & Recurrent & Mixed & Mixed \\
\hline Instrumented/fusion & Recurrent & Mixed & Nociceptive \\
\hline Instrumented/fusion & New & Leg & Neuropathic \\
\hline Instrumented/fusion & New & Back & Neuropathic \\
\hline Instrumented/fusion & New & Back & Mixed \\
\hline Instrumented/fusion & New & Back & Nociceptive \\
\hline Instrumented/fusion & New & Mixed & Neuropathic \\
\hline Instrumented/fusion & New & Mixed & Mixed \\
\hline Instrumented/fusion & New & Mixed & Nociceptive \\
\hline
\end{tabular}

\begin{tabular}{|c|c|c|c|}
\hline$U$ & $U$ & $U$ & $A$ \\
\hline$U$ & $U$ & $U$ & $A$ \\
\hline$U$ & $U$ & $U$ & $A$ \\
\hline$U$ & $U$ & $I$ & $A$ \\
\hline$U$ & $U$ & $U$ & $A$ \\
\hline$U$ & $U$ & $U$ & $A$ \\
\hline$U$ & $U$ & $U$ & $A$ \\
\hline$U$ & $U$ & $U$ & $A$ \\
\hline$U$ & $U$ & $U$ & $A$ \\
\hline$U$ & $U$ & $U$ & $A$ \\
\hline$U$ & $U$ & $I$ & $A$ \\
\hline$U$ & $U$ & $U$ & $A$ \\
\hline$U$ & $U$ & $U$ & $A$ \\
\hline$U$ & $U$ & $U$ & $A$ \\
\hline$U$ & $U$ & $A$ & $A$ \\
\hline$A$ & $U$ & $U$ & $U$ \\
\hline$A$ & $U$ & $U$ & $A$ \\
\hline$A$ & $U$ & $I$ & $A$ \\
\hline$U$ & $U$ & $U$ & $U$ \\
\hline$U$ & $U$ & $U$ & $A$ \\
\hline$U$ & $U$ & $I$ & $A$ \\
\hline
\end{tabular}

$\mathrm{CON}=$ conservative treatment

MIN = minimally invasive treatment

$\mathrm{NEU}=$ neurostimulation

Appropriate

$\mathrm{ROP}=$ re-operation

Uncertain

Inappropriate 
Table 8 Appropriateness of treatments for patients with no or inconclusive evidence for an anatomic abnormality

\begin{tabular}{|c|c|c|c|c|c|c|c|}
\hline \multirow[b]{2}{*}{$\begin{array}{l}\text { Previous } \\
\text { Surgery }\end{array}$} & \multirow[b]{2}{*}{$\begin{array}{l}\text { Onset } \\
\text { of pain }\end{array}$} & \multirow[b]{2}{*}{$\begin{array}{l}\text { Location } \\
\text { of pain }\end{array}$} & \multirow[b]{2}{*}{$\begin{array}{l}\text { Type } \\
\text { of pain }\end{array}$} & \multicolumn{4}{|c|}{ Treatment } \\
\hline & & & & CON & MIN & NEU & ROP \\
\hline Non-instrumented & Remaining & Leg & Neuropathic & $U$ & $\mathrm{U}$ & $\bar{A}$ & I \\
\hline Non-instrumented & Remaining & Back & Neuropathic & A & $\mathrm{U}$ & $\mathrm{U}$ & I \\
\hline Non-instrumented & Remaining & Back & Mixed & $\bar{A}$ & $\mathrm{U}$ & $U$ & I \\
\hline Non-instrumented & Remaining & Back & Nociceptive & A & $\mathrm{U}$ & I & I \\
\hline Non-instrumented & Remaining & Mixed & Neuropathic & A & $\mathrm{U}$ & A & I \\
\hline Non-instrumented & Remaining & Mixed & Mixed & A & $\mathrm{U}$ & A & I \\
\hline Non-instrumented & Remaining & Mixed & Nociceptive & A & A & $U$ & I \\
\hline Non-instrumented & Recurrent & Leg & Neuropathic & A & $\mathrm{U}$ & A & I \\
\hline Non-instrumented & Recurrent & Back & Neuropathic & A & $\mathrm{U}$ & A & I \\
\hline Non-instrumented & Recurrent & Back & Mixed & A & $\mathrm{U}$ & $\mathrm{U}$ & I \\
\hline Non-instrumented & Recurrent & Back & Nociceptive & A & $\mathrm{U}$ & I & I \\
\hline Non-instrumented & Recurrent & Mixed & Neuropathic & A & $U$ & U & I \\
\hline Non-instrumented & Recurrent & Mixed & Mixed & $\mathrm{A}$ & $\mathrm{U}$ & $\mathrm{U}$ & I \\
\hline Non-instrumented & Recurrent & Mixed & Nociceptive & A & $\mathrm{U}$ & $\mathrm{U}$ & I \\
\hline Non-instrumented & New & Leg & Neuropathic & A & $\mathrm{U}$ & A & I \\
\hline Non-instrumented & New & Back & Neuropathic & A & $\mathrm{U}$ & $\mathrm{U}$ & I \\
\hline Non-instrumented & New & Back & Mixed & A & $\mathrm{U}$ & $\mathrm{U}$ & I \\
\hline Non-instrumented & New & Back & Nociceptive & $\bar{A}$ & $U$ & I & I \\
\hline Non-instrumented & New & Mixed & Neuropathic & A & $\mathrm{U}$ & A & I \\
\hline Non-instrumented & New & Mixed & Mixed & A & $U$ & $U$ & I \\
\hline Non-instrumented & New & Mixed & Nociceptive & A & $\mathrm{U}$ & $\mathrm{U}$ & I \\
\hline
\end{tabular}

\begin{tabular}{|l|l|l|l|}
\hline Instrumented/fusion & Remaining & Leg & Neuropathic \\
\hline Instrumented/fusion & Remaining & Back & Neuropathic \\
\hline Instrumented/fusion & Remaining & Back & Mixed \\
\hline Instrumented/fusion & Remaining & Back & Nociceptive \\
\hline Instrumented/fusion & Remaining & Mixed & Neuropathic \\
\hline Instrumented/fusion & Remaining & Mixed & Mixed \\
\hline Instrumented/fusion & Remaining & Mixed & Nociceptive \\
\hline Instrumented/fusion & Recurrent & Leg & Neuropathic \\
\hline Instrumented/fusion & Recurrent & Back & Neuropathic \\
\hline Instrumented/fusion & Recurrent & Back & Mixed \\
\hline Instrumented/fusion & Recurrent & Back & Nociceptive \\
\hline Instrumented/fusion & Recurrent & Mixed & Neuropathic \\
\hline Instrumented/fusion & Recurrent & Mixed & Mixed \\
\hline Instrumented/fusion & Recurrent & Mixed & Nociceptive \\
\hline Instrumented/fusion & New & Leg & Neuropathic \\
\hline Instrumented/fusion & New & Back & Neuropathic \\
\hline Instrumented/fusion & New & Back & Mixed \\
\hline Instrumented/fusion & New & Back & Nociceptive \\
\hline Instrumented/fusion & New & Mixed & Neuropathic \\
\hline Instrumented/fusion & New & Mixed & Mixed \\
\hline Instrumented/fusion & New & Nociceptive \\
\hline
\end{tabular}

\begin{tabular}{|c|c|c|c|}
\hline A & $U$ & A & I \\
\hline$A$ & $\mathrm{U}$ & $\mathrm{U}$ & I \\
\hline $\mathrm{A}$ & $\mathrm{U}$ & $\mathrm{U}$ & I \\
\hline A & $U$ & I & I \\
\hline $\bar{A}$ & $\bar{U}$ & $\bar{A}$ & I \\
\hline A & $\mathrm{U}$ & A & I \\
\hline$A$ & $\mathrm{U}$ & $U$ & I \\
\hline$A$ & $U$ & A & I \\
\hline A & $U$ & $U$ & I \\
\hline A & $U$ & $U$ & I \\
\hline A & U & I & I \\
\hline A & $U$ & A & I \\
\hline A & $U$ & A & I \\
\hline$A$ & $\mathrm{U}$ & $\mathrm{U}$ & I \\
\hline$A$ & $\mathrm{U}$ & $A$ & I \\
\hline A & U & $U$ & I \\
\hline$A$ & $\mathrm{U}$ & $\mathrm{U}$ & I \\
\hline A & U & I & I \\
\hline A & U & A & I \\
\hline $\mathrm{A}$ & $\mathrm{U}$ & A & I \\
\hline A & U & I & I \\
\hline
\end{tabular}

CON = conservative treatment

MIN = minimally invasive treatment

$\mathrm{NEU}=$ neurostimulation

ROP $=$ re-operation
Appropriate

Uncertain

Inappropriate

\section{References}

1. Sivasubramaniam V, Patel HC, Ozdemir BA, Papadopoulos MC (2015) Trends in hospital admissions and surgical procedures for degenerative lumbar spine disease in England: a 15-year timeseries study. BMJ Open 5(12):e009011. https://doi.org/10.1136/ bmjopen-2015-009011

2. Bernstein DN, Brodell D, Li Y, Rubery PT, Mesfin A (2017) Impact of the economic downturn on elective lumbar spine surgery in the United States: a national trend analysis, 2003-2013. Global Spine J 7:213-219. https://doi.org/10.1177/2192568217 694151

3. Parker SL, Mendenhall SK, Godil SS, Sivasubramanian P, Cahill K, Ziewacz J, McGirt MJ (2015) Incidence of low back pain after lumbar discectomy for herniated disc and its effect on patientreported outcomes. Clin Orthop Relat Res 473:1988-1999. https ://doi.org/10.1007/s11999-015-4193-1

4. Strömqvist PF, Fritzel P, Hägg O, Knutsson B, Sanden B (2014) SWESPINE, The Swedish Spine Register. 2014 Report. Swedish Society of Spinal Surgeons. http://www.4s.nu/pdf/Report_2014_ Swespine_Engl_ver_141204.pdf. Accessed 8 May 2018

5. Weir S, Samnaliev M, Kuo TC, Ni Choitir C, Tierney TS, Cumming D, Bruce J, Manca A, Taylor RS, Eldabe S (2017) The incidence and healthcare costs of persistent postoperative pain following lumbar spine surgery in the UK: a cohort study using the Clinical Practice Research Datalink (CPRD) and Hospital Episode Statistics (HES). BMJ Open 7:e017585. https://doi.org/10.1136/ bmjopen-2017-017585 
6. Chan CW, Peng P (2011) Failed back surgery syndrome. Pain Med 12:577-606. https://doi.org/10.1111/j.1526-4637.2011.01089.x

7. Thomson S (2013) Failed back surgery syndrome—definition, epidemiology and demographics. Br J Pain 7:56-59. https://doi. org/10.1177/2049463713479096

8. Vleggeert-Lankamp CL, Arts MP, Jacobs WC, Peul WC (2013) Failed back (surgery) syndrome: time for a paradigm shift. Br J Pain 7:48-55. https://doi.org/10.1177/2049463713479095

9. Rigoard P, Desai MJ, Taylor RS (2015) Failed back surgery syndrome: what's in a name? A proposal to replace "FBSS" by "POPS"... Neurochirurgie 61(Suppl 1):S16-S21. https://doi. org/10.1016/j.neuchi.2014.12.001

10. Wilson CA, Roffey DM, Chow D, Alkherayf F, Wai EK (2016) A systematic review of preoperative predictors for postoperative clinical outcomes following lumbar discectomy. Spine J 16:1413 1422. https://doi.org/10.1016/j.spinee.2016.08.003

11. Suri P, Pearson AM, Zhao W, Lurie JD, Scherer EA, Morgan TS, Weinstein JN (2017) Pain recurrence after discectomy for symptomatic lumbar disc herniation. Spine 42:755-763. https:// doi.org/10.1097/BRS.0000000000001894

12. Blond S, Mertens P, David R, Roulaud M, Rigoard P (2015) From "mechanical" to "neuropathic" back pain concept in FBSS patients. A systematic review based on factors leading to the chronification of pain (part C). Neurochirurgie 61(Suppl 1):S45S56. https://doi.org/10.1016/j.neuchi.2014.11.001

13. Shamji MF, Shcharinsky A (2015) Use of neuropathic pain questionnaires in predicting persistent postoperative neuropathic pain following lumbar discectomy for radiculopathy. J Neurosurg Spine 9:1-7. https://doi.org/10.3171/2015.4.SPINE141310

14. Markman JD, Kress BT, Frazer M, Hanson R, Kogan V, Huang JH (2015) Screening for neuropathic characteristics in failed back surgery syndromes: challenges for guiding treatment. Pain Med 16:520-530. https://doi.org/10.1111/pme.12612

15. Lamartina C, Berjano P (2014) Classification of sagittal imbalance based on spinal alignment and compensatory mechanisms. Eur Spine J 23:1177-1189. https://doi.org/10.1007/s0058 6-014-3227-9

16. Le Huec JC, Faundez A, Dominguez D, Hoffmeyer P, Aunoble S (2015) Evidence showing the relationship between sagittal balance and clinical outcomes in surgical treatment of degenerative spinal diseases: a literature review. Int Orthop 39:87-95. https:// doi.org/10.1007/s00264-014-2516-6

17. El Barzouhi A, Verwoerd AJ, Peul WC, Verhagen AP, Lycklama à Nijeholt GJ, Van der Kallen BF, Koes BW, Vleggeert-Lankamp CL; Leiden-The Hague Spine Intervention Prognostic Study Group (2016) Prognostic value of magnetic resonance imaging findings in patients with sciatica. J Neurosurg Spine 24:978-985. https://doi.org/10.3171/2015.10.SPINE15858

18. Azimi P, Azhari S, Benzel EC, Khayat Kashany H, Nayeb Aghaei H, Mohammadi HR, Ebrahimi M (2016) Outcomes of surgery in patients with lumbar spinal canal stenosis: comparison of three types of stenosis on MRI. PLoS ONE 11:e0158041. https://doi. org/10.1371/journal.pone.0158041

19. Grider JS, Manchikanti L, Carayannopoulos A, Sharma ML, Balog CC, Harned ME, Grami V, Justiz R, Nouri KH, Hayek SM, Vallejo R, Christo PJ (2016) Effectiveness of spinal cord stimulation in chronic spinal pain: a systematic review. Pain Physician 19:E33-E54

20. Helm S 2nd, Racz GB, Gerdesmeyer L, Justiz R, Hayek SM, Kaplan ED, El Terany MA, Knezevic NN (2016) Percutaneous and endoscopic adhesiolysis in managing low back and lower extremity pain: a systematic review and meta-analysis. Pain Physician 19:E245-E282

21. Cho JH, Lee JH, Song KS, Hong JY, Joo YS, Lee DH, Hwang CJ, Lee CS (2017) Treatment outcomes for patients with failed back surgery. Pain Physician 20:E29-E43
22. Amirdelfan K, Webster L, Poree L, Sukul V, McRoberts P (2017) Treatment options for failed back surgery syndrome patients with refractory chronic pain: an evidence based approach. Spine 42(Suppl 14):S41-S52. https://doi.org/10.1097/BRS.0000000000 002217

23. Manchikanti L, Abdi S, Atluri S et al (2013) An update of comprehensive evidence-based guidelines for interventional techniques in chronic spinal pain. Part II: guidance and recommendations. Pain Physician 16(Suppl):S49-S283

24. National Institute for Health and Care Excellence (2008) Spinal cord stimulation for chronic pain of neuropathic or ischaemic origin. https://www.nice.org.uk/guidance/ta159. Accessed 8 May 2018

25. Ganty P, Sharma M (2012) Failed back surgery syndrome: a suggested algorithm of care. Br J Pain 6:153-161. https://doi. org/10.1177/2049463712470222

26. Assaker R, Zairi F (2015) Failed back surgery syndrome: to reoperate or not to re-operate? A retrospective review of patient selection and failures. Neurochirurgie 61(Suppl 1):S77-S82. https ://doi.org/10.1016/j.neuchi.2014.10.108

27. Van Buyten JP, Linderoth B (2010) "The failed back surgery syndrome": definition and therapeutic algorithms — an update. Eur J Pain Suppl 4:273-286

28. Brook RH, Chassin MR, Fink A, Solomon DH, Kosecoff J, Park RE (1986) A method for the detailed assessment of the appropriateness of medical technologies. Int J Technol Assess Health Care 2:53-63

29. Fitch K, Bernstein SJ, Aguilar MD, Burnand B, LaCalle JR, Lazaro P, Van het Loo M, McDonnell J, Vader JP, Kahan JP (2001) The RAND/UCLA Appropriateness Method. User's manual. RAND Corporation, Santa Monica (CA). https://www. rand.org/pubs/monograph_reports/MR1269.html. Accessed 8 May 2018

30. Lawson EH, Gibbons MM, Ko CY, Shekelle PG (2012) The appropriateness method has acceptable reliability and validity for assessing overuse and underuse of surgical procedures. J Clin Epidemiol 65:1133-1143. https://doi.org/10.1016/j.jclin epi.2012.07.002

31. Shekelle P (2004) The appropriateness method. Med Decis Mak 24:228-231

32. Shekelle PG, Kahan JP, Bernstein SJ, Leape LL, Kamberg CJ, Park RE (1998) The reproducibility of a method to identify the overuse and underuse of medical procedures. N Engl J Med 338:1888-1895. https://doi.org/10.1056/NEJM199806253382607

33. Tobacman JK, Scott IU, Cyphert S, Zimmerman B (1999) Reproducibility of measures of overuse of cataract surgery by three physician panels. Med Care 37:37-45

34. Quintana JM, Escobar A, Arostegui I, Bilbao A, Azkarate J, Goenaga JI, Arenaza JC (2006) Health-related quality of life and appropriateness of knee or hip joint replacement. Arch Intern Med 166:220-226. https://doi.org/10.1001/archinte.166.2.220

35. Hemingway H, Crook AM, Feder G, Banerjee S, Dawson JR, Magee P, Philpott S, Sanders J, Wood A, Timmis AD (2001) Underuse of coronary revascularization procedures in patients considered appropriate candidates for revascularization. N Engl J Med 344:645-654. https://doi.org/10.1056/NEJM20010301344 0906

36. International Association for the Study of Pain (1994) Update of "pain terms, a current list with definitions and notes on usage". In: Merskey H, Bogduk N (eds) Classification of chronic pain. IASP Task Force on Taxonomy, 2nd edn. IASP Press, Seattle, pp 209-214. https://www.iasp-pain.org. Accessed 8 May 2018

37. Ferraro F, Jacopetti M, Spallone V, Padua L, Traballesi M, Brunelli S, Cantarella C, Ciotti C, Coraci D, Dalla Toffola E, Mandrini S, Morone G, Pazzaglia C, Romano M, Schenone A, Togni R, Tamburin S, Italian Consensus conference on pain in 
neurorehabilitation (ICCPN) (2016) Diagnosis and treatment of pain in plexopathy, radiculopathy, peripheral neuropathy and phantom limb pain. Evidence and recommendations from the Italian Consensus Conference on Pain on Neurorehabilitation. Eur J Phys Rehabil Med 52:855-866

38. Deng Y, Luo L, Hu Y, Fang K, Liu J (2016) Clinical practice guidelines for the management of neuropathic pain: a systematic review. BMC Anesthesiol 16:12. https://doi.org/10.1186/s1287 1-015-0150-5

39. North RB, Kidd DH, Farrokhi F, Piantadosi SA (2005) Spinal cord stimulation versus repeated lumbosacral spine surgery for chronic pain: a randomized, controlled trial. Neurosurgery 56:98-106

40. Kumar K, Taylor RS, Jacques L, Eldabe S, Meglio M, Molet J, Thomson S, O'Callaghan J, Eisenberg E, Milbouw G, Buchser E, Fortini G, Richardson J, North RB (2007) Spinal cord stimulation versus conventional medical management for neuropathic pain: a multicentre randomised controlled trial in patients with failed back surgery syndrome. Pain 132:179-188. https://doi. org/10.1016/j.pain.2007.07.028

41. Rigoard P, Desai MJ, North RB, Taylor RS, Annemans L, Greening C, Tan Y, Van den Abeele C, Shipley J, Kumar K (2013) Spinal cord stimulation for predominant low back pain in failed back surgery syndrome: study protocol for an international multicenter randomized controlled trial (PROMISE study). Trials 14:376. https://doi.org/10.1186/1745-6215-14-376
42. Finnerup NB, Haroutounian S, Kamerman P, Baron R, Bennett DL, Bouhassira D, Cruccu G, Freeman R, Hansson P, Nurmikko T, Raja SN, Rice AS, Serra J, Smith BH, Treede RD, Jensen TS (2016) Neuropathic pain: an updated grading system for research and clinical practice. Pain 157:1599-1606. https://doi. org/10.1097/j.pain.0000000000000492

43. Förster M, Mahn F, Gockel U, Brosz M, Freynhagen R, Tölle TR, Baron R (2013) Axial low back pain: one painful area-many perceptions and mechanisms. PLoS ONE 8:e68273. https://doi. org/10.1371/journal.pone.0068273

44. Bogduk N (2009) On the definitions and physiology of back pain, referred pain, and radicular pain. Pain 147:17-19. https://doi. org/10.1016/j.pain.2009.08.020

45. Nijs J, Apeldoorn A, Hallegraeff H, Clark J, Smeets R, Malfliet A, Girbes EL, De Kooning M, Ickmans K (2015) Low back pain: guidelines for the clinical classification of predominant neuropathic, nociceptive, or central sensitization pain. Pain Physician 18:E333-E346

46. Attal N, Perrot S, Fermanian J, Bouhassira D (2011) The neuropathic components of chronic low back pain: a prospective multicenter study using the DN4 Questionnaire. J Pain 12:1080-1087. https://doi.org/10.1016/j.jpain.2011.05.006

47. Rigoard P, Blond S, David R, Mertens P (2015) Pathophysiological characterisation of back pain generators in failed back surgery syndrome (part B). Neurochirurgie 61(Suppl 1):S35-S44. https:// doi.org/10.1016/j.neuchi.2014.10.104

\section{Affiliations}

Volker M. Tronnier ${ }^{1}$. Sam Eldabe ${ }^{2}$ Jörg Franke ${ }^{3}$ Frank Huygen $^{4}$. Philippe Rigoard ${ }^{5,6}$. Javier de Andres Ares ${ }^{7}$. Richard Assaker $^{8}$. Alejandro Gomez-Rice ${ }^{9}$ Marco La Grua ${ }^{10}$. Maarten Moens ${ }^{11}$. Lieven Moke ${ }^{12,13}$. Christophe Perruchoud ${ }^{14}$. Nasir A. Quraishi ${ }^{15}$. Dominique A. Rothenfluh ${ }^{16}$. Pedram Tabatabaei ${ }^{17}$. Koen Van Boxem ${ }^{18} \cdot$ Carmen Vleggeert-Lankamp $^{19} \cdot$ Björn Zoëga $^{20} \cdot$ Herman J. Stoevelaar $^{21}$

Herman J. Stoevelaar

herman.stoevelaar@ismar.com

1 Department of Neurosurgery, University Hospital Schleswig-Holstein, Lübeck, Germany

2 Department of Pain Medicine, The James Cook University Hospital, Middlesbrough, UK

3 Department of Orthopedics, Klinikum Magdeburg, Magdeburg, Germany

4 Department of Anesthesiology and Pain Management, Erasmus University Medical Center, Rotterdam, The Netherlands

5 Neurosurgical Department, University Hospital Poitiers, Poitiers, France

6 CNRS, UPR 3346, Futuroscope, Poitiers, France

7 Pain Unit, Department of Anaesthetics, University Hospital La Paz, Madrid, Spain

8 Department of Neurosurgery, University Hospital Lille, Lille, France

9 Spine Unit, University Hospital Getafe, Madrid, Spain

10 Multidisciplinary Spine Center, Santa Maria Maddalena Hospital, Occhiobello, Italy

11 Department of Neurosurgery, University Hospital Brussels, Brussels, Belgium
12 Department of Development and Regeneration KU Leuven, Institute for Orthopaedic Research and Training (IORT) KU Leuven, Leuven, Belgium

13 Division of Orthopaedics, University Hospitals Leuven, Leuven, Belgium

14 Clinique de la Douleur, Hôpital de la Tour, Geneva, Switzerland

15 Centre for Spine Studies \& Surgery, Queen's Medical Centre, Nottingham, UK

16 Division of Spinal Surgery, Oxford University Hospitals NHS Foundation Trust, Oxford, UK

17 University of Umeå, Umeå, Sweden

18 Department of Anaesthesiology, Intensive Care and Pain Management, Hospital Oost-Limburg, Genk, Belgium

19 Department of Neurosurgery, Leiden University Medical Center, Leiden, The Netherlands

20 Stockholm Spine Center, Stockholm, Sweden

21 Centre for Decision Analysis and Support, Ismar Healthcare, Oudewater, The Netherlands 